\title{
Stress-Strain Relationships in Yarns Subjected to Rapid Impact Loading: 1. Equipment, Testing Procedure, and Typical Results ${ }^{1}$
}

\author{
Walter K. Stone, Herbert F. Schiefer, and George Fox ${ }^{2}$
}

\begin{abstract}
Equipment is described for elongating yarns by longitudinal impact at velocities ranging from 10 to 100 meters per second. The rate of straining at impact varies from about 100,000 to 500,000 precent per minute.

A procedure is discussed for obtaining load-elongation curves for loading and for unloading of the specimen and for loading to rupture in a time interval of only a few milliseconds. The results of a typical loading and unloading test are presented.
\end{abstract}

\section{Introduction}

Textile materials in processing and use are subjected ever more frequently to higher rates of straining. For example, in high-speed industrial sewing the thread is subjected to impact velocities ranging from 1 to $10 \mathrm{~m} / \mathrm{sec}$ as often as 5,000 times per minute. This results in high-frequency cyclic accelerations of the thread, which may equal several million centimeters per second per second. These high accelerations of the thread produce forces that approach, and may even exceed, the breaking strength of the thread. Similar conditions may be attained in high-speed processing of fibers, such as carding and combing or the weaving and knitting of yarns into fabrics; in the cord of an airplane tire during landing; in the safety line when a structural worker attached to it falls; and in the fabric, shroud lines, and webbing during the opening of a parachute.

The present work was undertaken to provide basic information on the behavior of textile materials when strained at very high rates; to relate the results to the molecular structure of the fibers and to the geometry of the yarns and fabrics; and finally, to indicate the applications of this information to safety engineering, to industrial processing of textiles, to the development of fibers of improved impact properties, and to industrial and military end uses of textile structures for specific performance requirements.

This is the first of a series of papers on rapid impact testing. In this paper equipment and procedures for this purpose are described and typical results are presented.

The stress-strain behavior of textile and other materials has been thoroughly investigated at rates of straining ordinarily referred to as "static" tensile testing. The velocity of the moving head of the testing machine in static testing is usually between about 0.1 and 10 inches per minute $\left(4 \times 10^{-5}\right.$ and $4 \times 10^{-3} \mathrm{~m} / \mathrm{sec}$ ). The corresponding rates of straining

1 This work was sponsored by the Office of the Quartermaster General, Department of the Army, and was presented in part at the September 1953 and 1954 meetings of The Fiber Society, and also at the November 1954 meeting of the Society of Rheology.

2 Present address, Lehigh University, Bethlehem, Pa. range from about 1 to 100 percent per minute for textile materials. In impact testing, usually made by dropping a mass a known height or by allowing a pendulum to swing freely through 90 to 180 degrees to rupture the specimen, the velocity at impact is usually limited by room dimensions to values between 1,000 and $20,000 \mathrm{in} . / \mathrm{min}$. (0.4 and $8 \mathrm{~m} / \mathrm{sec}$ ). The corresponding rates of straining range from about 10,000 to 200,000 percent per minute. Although excellent work has been reported in this velocity range $[1$ to 10$],{ }^{3}$ the information concerning the stress-strain behavior of textile and other materials is not as complete as for static testing. The information at higher impact velocities, 20,000 to $10,000,000 \mathrm{in} . / \mathrm{min}$ ( 8 to $4,000 \mathrm{~m} / \mathrm{sec}$ ) or rates of straining ranging from about 200,000 to $100,000,000$ percent per minute, is incomplete. Much of the published work in this velocity range is theoretical or has been confined to very small strains [11 to 35]. Meredith [7] has recently published excellent stressstrain relationships for viscose rayon, acetate, silk, and nylon yarns for rates of straining between 0.05 and 70,000 percent per minute. The rates of straining obtainable with the equipment described in this paper are between about 100,000 and $1,000,000$ percent per minute for textile materials. Even this maximum rate of straining is considerably below the rates of straining that prevail when textile materials are tested at their critical velocities. ${ }^{4}$ These rates of straining are estimated to range from about $10,000,000$ to $100,000,000$ percent per minute.

\section{Equipment and Testing Procedure}

Equipment has been constructed at the National Bureau of Standards for applying longitudinal impacts, at velocities up to $100 \mathrm{~m} / \mathrm{sec}$, to one end of a specimen of textile fiber, yarn, cord, or other materials having similar dimensions. The rates of straining range from 100,000 to 500,000 percent per minute. A high-speed motion-picture camera and mirrors are used to photograph simultaneously the

\footnotetext{
${ }^{3}$ Figures in brackets indicate the literature references at the end of this paper. 4 The concept of critical velocity was suggested by von Kármán [32, 33] and has been discussed by Hoppmann [27] and by Andersson and Steenberg [11].
} 
positions of the head and tail ends of the specimen during the first few milliseconds from the time of impact. The stress-strain behavior of the specimen is then derived from the photographic record.

The specimen to be tested is usually $2 / 3 \mathrm{~m}$ long, but can be varied in length. One end is fastened to a head mass, hereafter termed "head," which is impacted. The other end is fastened to a tail mass, hereafter termed "tail." The head and tail, with a specimen of yarn attached to them, are shown in figure 1.

The manner of attaching the specimen is important. The specimen must not be damaged, high stress concentration must be avoided, and slippage must be minimized. An effective way of attaching a specimen is shown in figure 1. A small hole is drilled in the end of the head and the tail in such a way that it terminates in a helical groove on the surface. The bottom of the groove is coated with a rubber-like high-friction compound. The end of a specimen is threaded through the hole, wound in the groove, and snubbed under the shoulder of a recessed screw. It is apparent that as the longitudinal tension in the specimen is increased during an impact test the radial pressure of the specimen against the groove is also increased. The longitudinal stress is thus effectively transferred between the specimen and the head or tail through the increased contact friction. The effective length of the specimen is equal to the distance between the inner ends of the head and tail plus $1 \mathrm{~cm}$ at each end for the helical groove.

The tail and attached specimen are inserted in a tube, as shown in figure 2. The right portion of this tube is made of transparent plastic, so that the tail and a portion of the specimen are visible. The head is fitted into the left end of the tube. Two disks are

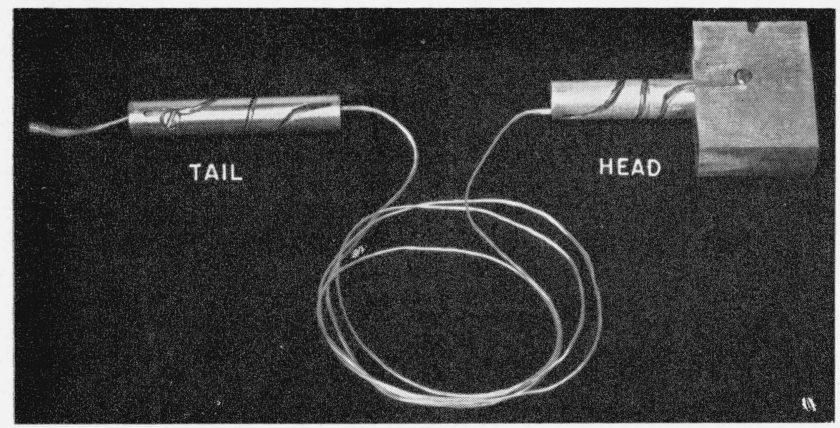

Figure 1. Yarn specimen fastened to head and tail for an impact test. attached to the middle portion of the tube to serve as the bearing shaft when the tube is inserted in the impact equipment for a test.

A portion of the impact equipment is shown in figure 3. The upper view shows the tube, with the head in a vertical position. Directly below the head and tube a portion of a heavy disk is visible. The disk can be rotated counterclockwise. Two lugs, called hammers, are attached to the disk. They are visible to the left of the head in the upper view of figure 3. In a test the speed of the disk may be adjusted to values between 5 and $50 \mathrm{rps}$. The peripheral speed of the hammers ranges from about 10 to $100 \mathrm{~m} / \mathrm{sec}$. A stroboscope is used to measure the speed of the disk.

The upper view of figure 3 shows the hammers in a position where a sector (not shown) attached to the disk closes an electric contact in a triggering circuit. When this circuit is closed a solenoid releases a springloaded cam. This cam rotates the tube containing the tail, specimen, and head through 90 degrees in less time than is required for one rotation of the hammers, even when the disk rotates at a speed as high as $50 \mathrm{rps}$. With the head in a horizontal position, lower view of figure 3 , the head will be struck by the hammers of the disk for the impact test of the specimen attached to the head.
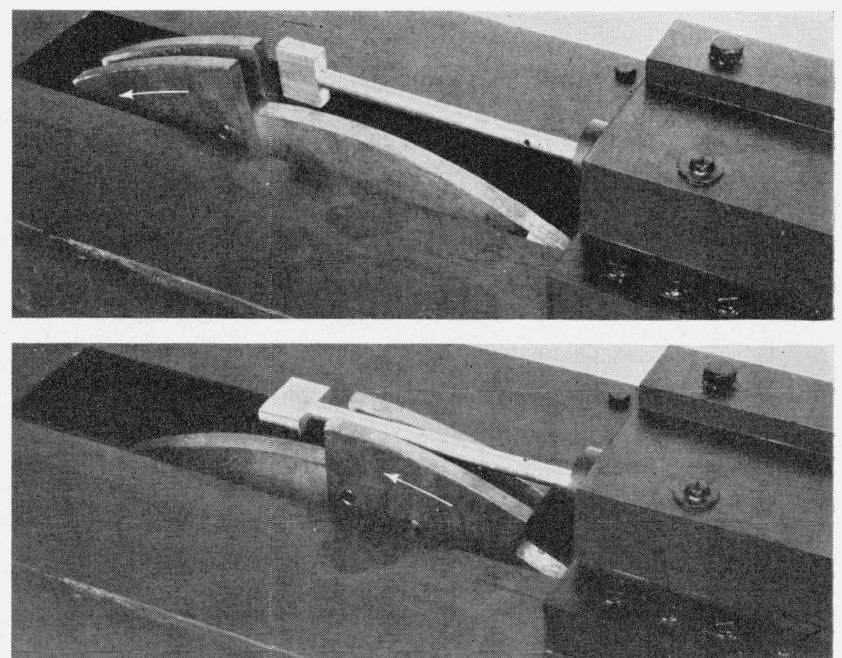

Figure 3. A portion of the impact equipment.

Upper view shows the head in a vertical position and hammers at the instant when a contact in the triggering circuit is closed by the disk. Lower view shows the head in a horizontal position and the hammers at the instant prior to impact of the head.

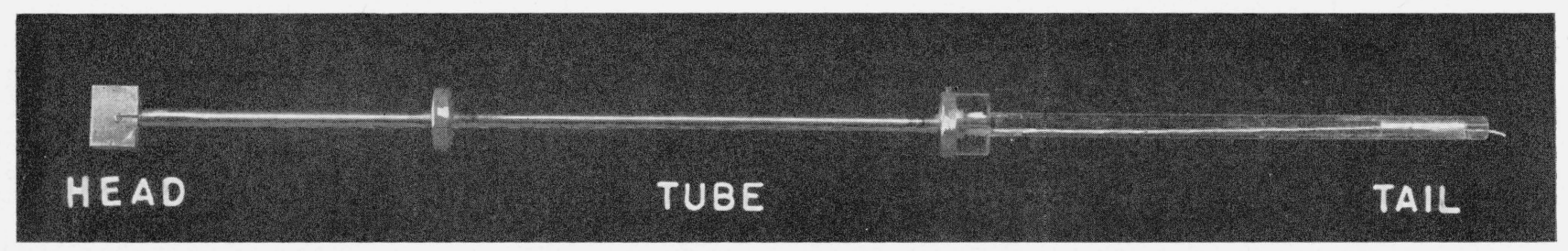

Figure 2. Tube containing yarn specimen and attached tail, with the head attached to left end of tube. 


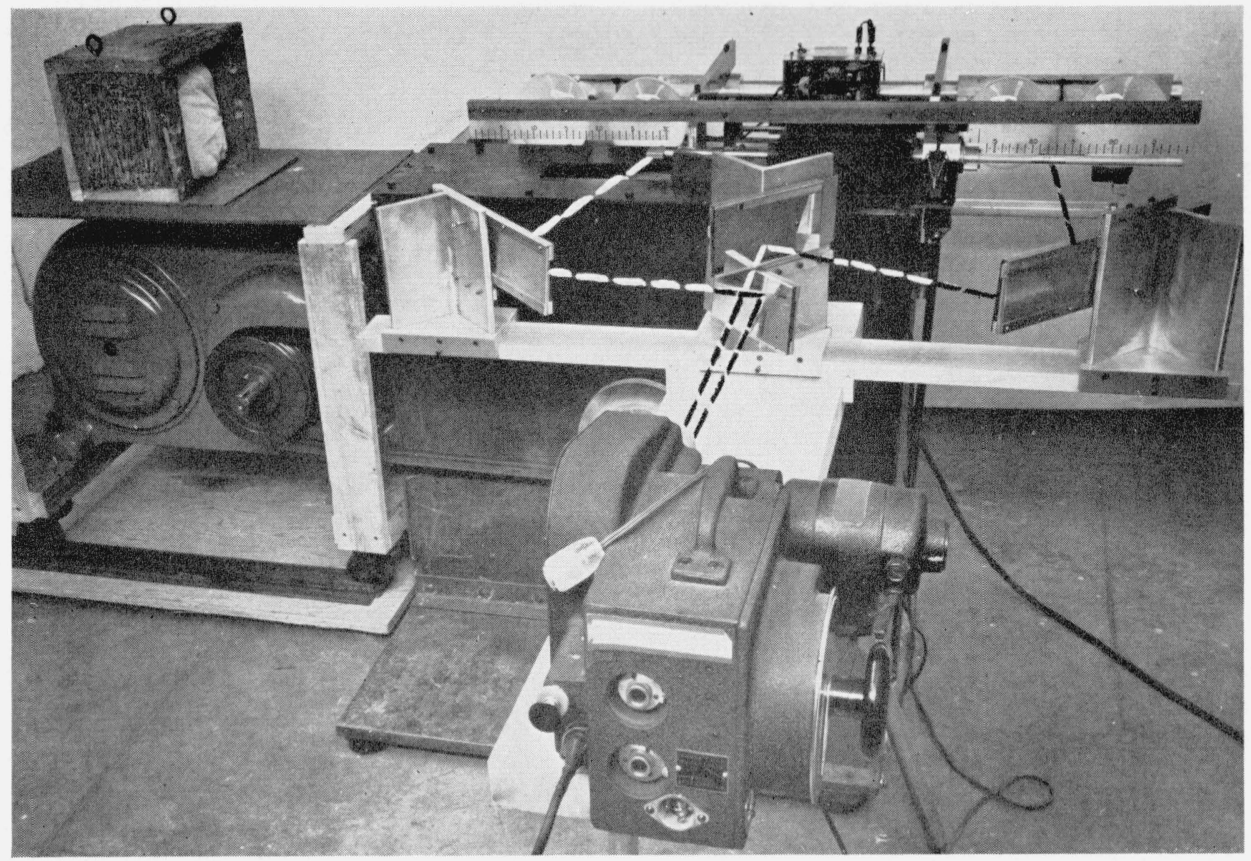

Figure 4. Assembly of impact-testing equipment.

Variable-speed motor at the left, with catch box above it; high-speed camera in the foreground; photoflood bulbs, scales, tube containing head, specimen, and tail in the background; mirror system in the center; broken lines to indicate paths of light beams from the head and tail.

The assembly of the impact-testing equipment is shown in figure 4. A 5-hp variable-speed motor, used for rotating the disk at high speed, is shown at the leit. Directly above it is a box in which the head is caught aifter impact. The tube containing the head, specimen, and tail is shown to the right of the box. Two scales, ruled in centimeters on transparent plastic, are shown directly above the tube. Photoflood bulbs are mounted directly in back of the tube. A high-speed motion-picture camera is shown in the foreground. A system of mirrors is mounted between the tube and camera. The paths of representative light beams from the head and tail are indicated by the broken lines. The mirrors are mounted on a metal base and can be readily adjusted to different horizontal positions. The mirrors can also be adjusted in their inclination so that the image of the tail and its scale appear above the image of the head and its scale in the field of view of the camera. The head and tail are photographed in silhouette, as shown in figure 5 .

Aitter adjusting the speed of the disk to the desired value for a test, and with the head, specimen, and tail in position, the motor of the camera and the photoflood bulbs are turned on. When the film has attained the desired speed, the camera closes an electric contact in the triggering circuit of the solenoid. This contact is in series with the solenoid, a series of batteries (alternating current of 60 cycles is not reliable for this purpose), and the contact on the disk referred to previously. The contact on the disk is closed the next time the hammers reach

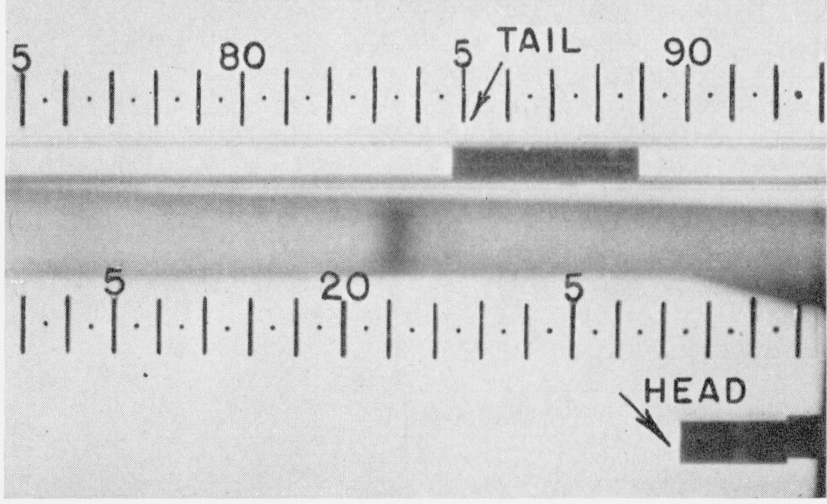

Figure 5. Camera field view of specimen ends before impact.

the position shown in the upper view of figure 3 . At this time the solenoid is energized and actuates a trigger to release the spring-loaded cam. The cam rotates the tube and head into a horizontal position (bottom view of fig. 3). The head will be struck by the hammers on the next rotation of the disk for the impact test. The motions of the head and tail aitter impact are recorded by the high-speed camera.

After impact, the head is thrown to the left (fig. 4) and is caught in the box above the variablespeed motor. The tail is usually caught in the box. In some tests it remains in the tube or is thrown out of the rear of the plastic tube by the reaction from the specimen after rupture has occurred. 


\section{Behavior of Specimen After Impact}

A few microseconds after impact, the head will attain a velocity exceeding that of the manner, and therefore will move in free flight ahead of the hammer. The sudden impact of the head produces a strain in the specimen where it is attached to the head. This strain depends on the impact velocity and on the material being tested. This strain and a tension approximately proportional to it will be propagated along the specimen toward the tail. When the strain reaches the tail it will be reflected and the reflected strain propagated toward the head. The strain and tension at the tail are approximately doubled upon reflection.

The propagation of the strain along the specimen and the successive reflections at the head and the tail will continue. At each reflection the strain and the tension are increased. The increased tension will cause a deceleration of the head and an acceleration of the tail. This process will continue until the rupture strain is reached and the specimen breaks, or until the velocity of the tail equals that of the head, at which time the specimen will be at maximum average strain and under maximum average tension, but both are below the rupture values. After this time the tension in the specimen will continue to decelerate the head and to accelerate the tail, so that the velocity of the tail will exceed that of the head. As soon as the velocity of the tail exceeds that of the head the strain will be relieved and the tension in the specimen will be decreased. This process of strain release and propagation is probably similar to that occurring during the increase of the strain, and will continue until all of the recoverable strain is relieved, at which time the tension will have been reduced to zero and the specimen will become slack. The specimen is thus loaded to a maximum tension and extension and then unloaded to zero tension and a set or extension in a total time of several milliseconds. Part of the set may be reduced by delayed recovery.

The propagation of the strain pulse after impact and subsequent reflections at the tail and head are indicated schematically in figure $6, \mathrm{~A}$ to $\mathrm{H}$. Before impact, the specimen is represented in $\mathrm{A}$ by a series of adjoining circular springs. After impact, in B, the circular spring next to the head is deformed into an ellipse, and the strain pulse is indicated by the adjacent cross-hatched circle and ellipse. The arrow indicates the direction of strain propagation. $\mathrm{C}$ and $\mathrm{D}$ show the arrival and reflection of the strain pulse at the tail. At this moment the tail is set in motion, and the ellipse before reflection is deformed to one of greater eccentricity after reflection. E indicates the arrival of the reflected strain pulse at the head. After reflection at the head, the strain pulse is shown in $\mathrm{F}$ as traveling toward the tail about midway between the head and tail. In $\mathrm{G}$ the strain pulse is shown as traveling toward the head after reflection at the tail and the high strain is indicated by the highly eccentric ellipses. After the next reflection at the head it is assumed that the rupture

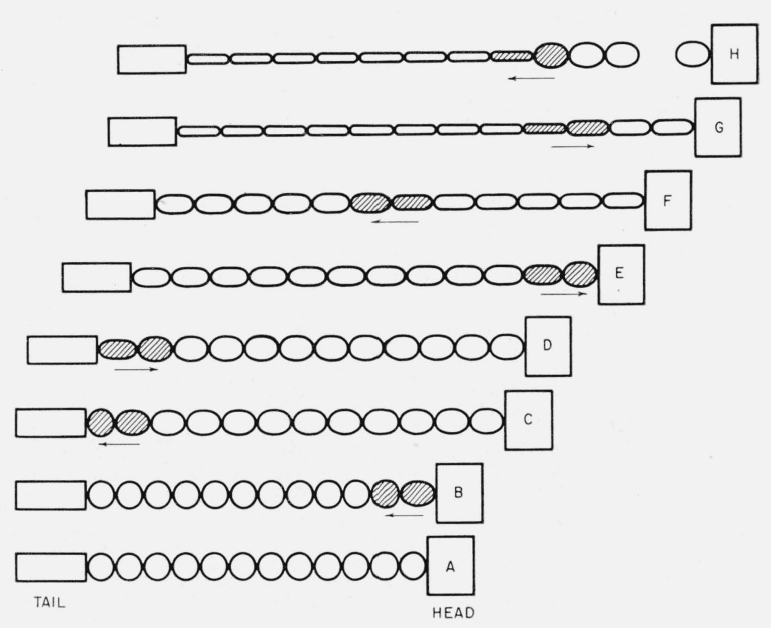

Figure 6. Schematic representation of strain propagation in specimen, indicated by adjoining circular springs, after impact of the head at an instant between $A$ and $B$.

Cross-hatched circle and ellipse represent the strain pulse.

strain is attained, and the ruptured specimen is shown in $\mathrm{H}$. After rupture, the strain is released. This condition is represented in $\mathrm{H}$ by the reconversion (recovery) of the ellipses of high eccentricity to ellipses of low eccentricity or to circles for complete recovery. The propagation of the strainrelease pulse is indicated by the arrow. The ruptured end will snap toward the tail with a very high velocity, and the momentum acquired by the specimen, when the strain-release pulse reaches the tail, may be sufficient to stop the tail or to reverse its motion.

\section{Tests on a Nylon Yarn}

A specimen of nylon yarn was fastened at one end to a head weighing $19.82 \mathrm{~g}$ and at the other end to a tail of $4.85 \mathrm{~g}$, the length between fastenings being $65 \mathrm{~cm}$. The head was impacted at a velocity of 30 $\mathrm{m} / \mathrm{sec}$.

The motions of the head and tail were recorded photographically by means of high-speed motion pictures taken at a rate of 2,630 frames per second. The sequence of pictures is shown in figure 7 , beginning with two frames before impact, upper lefthand corner, and ending after release of the strain, lower right-hand corner. It can be seen that before impact in frames 1 and 2 the positions of the head and tail remain stationary relative to the fixed centimeter scale, which is photographed on each frame. After impact, which occurred between frames 2 and 3 , the head moves relative to the fixed scale until it finally disappears from the field of view of the camera. The tail, on the other hand, moves very little for several frames after impact. It then speeds up until in frame 10 it moves the same amount as the head. Thereafter it moves further per frame than the head; after frame 16 the distance moved per frame is maximum and essentially constant. 

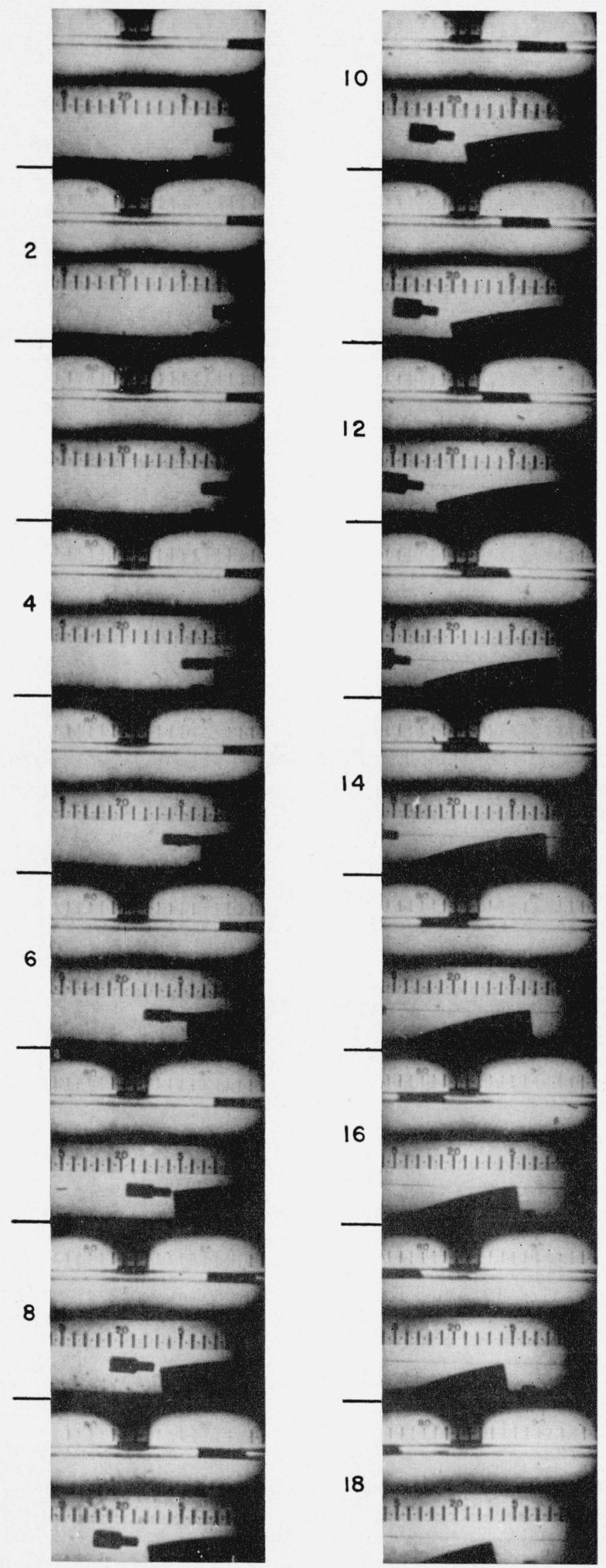

Figure 7. Film strips showing motion of head and tail.

Inpact occurs between frames 2 and 3 , maximum tension between frames 10 and 11.

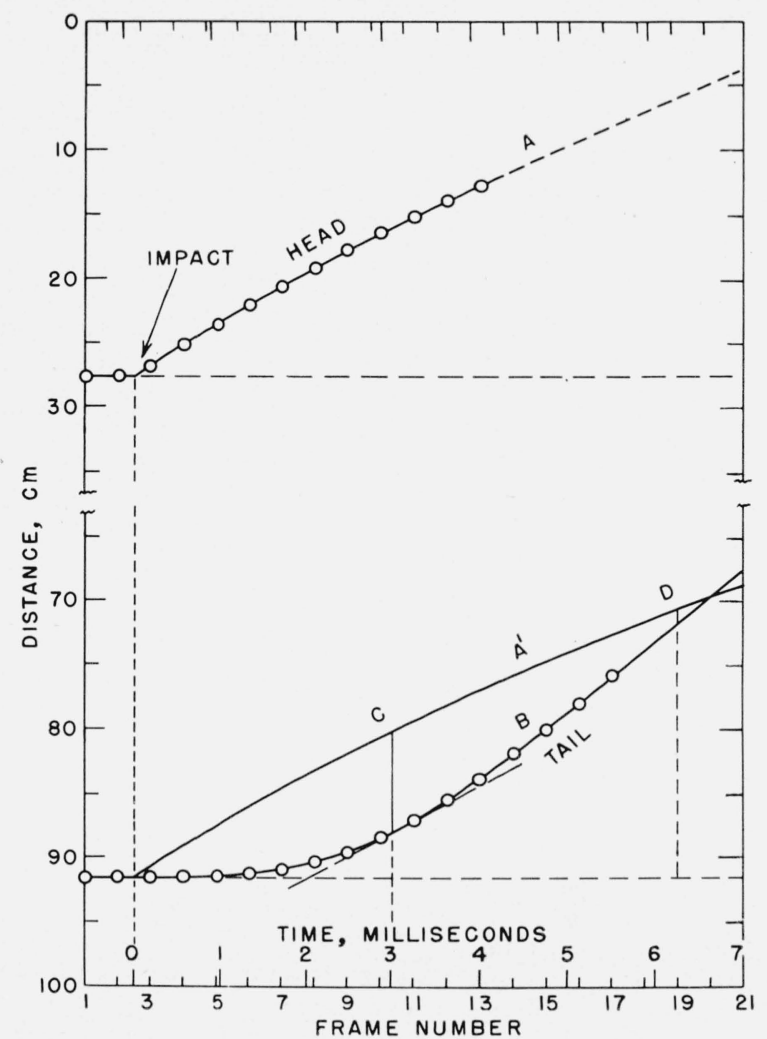

FIgure 8. Position of head and of tail on successive frames in an impact test of a nylon yarn.

The positions of the head and of the tail on each frame were carefully measured, relative to the fixed scale, with a precision micrometer. These positions are plotted in figure 8 against frame number and also against time in milliseconds. The resulting curves will hereafter be referred to as distance-frame or distance-time curves. Zero time refers to the instant of impact and is obtained by extrapolating the distance-frame curve, $A$, of the head after impact back to the distance-frame curve of the head before impact. The point of intersection of these two curves is taken as the instant of impact.

The distance-time curve of the head is slightly concave downward, indicating that the head is slowing down. The slope of this curve at any point (time) is equal to the velocity of the head at that time. The velocity-time curve of the head is plotted in figure 9 . Immediately after impact the velocity of the head is about $45 \mathrm{~m} / \mathrm{sec}$. At 4 msec after impact it is reduced to $30 \mathrm{~m} / \mathrm{sec}$.

The distance-time curve of the tail, $\mathrm{B}$ of figure 8 , is concave upward, indicating that its velocity increases with time. At 3 msec the slope of the distancetime curve for the tail is equal to that for the head, indicating that the velocities of the head and the tail are equal. The velocity-time curve of the tail is also plotted in figure 9. The velocity of the tail is zero before impact, then increases slowly immediately after impact. It increases most rapidly at 3 


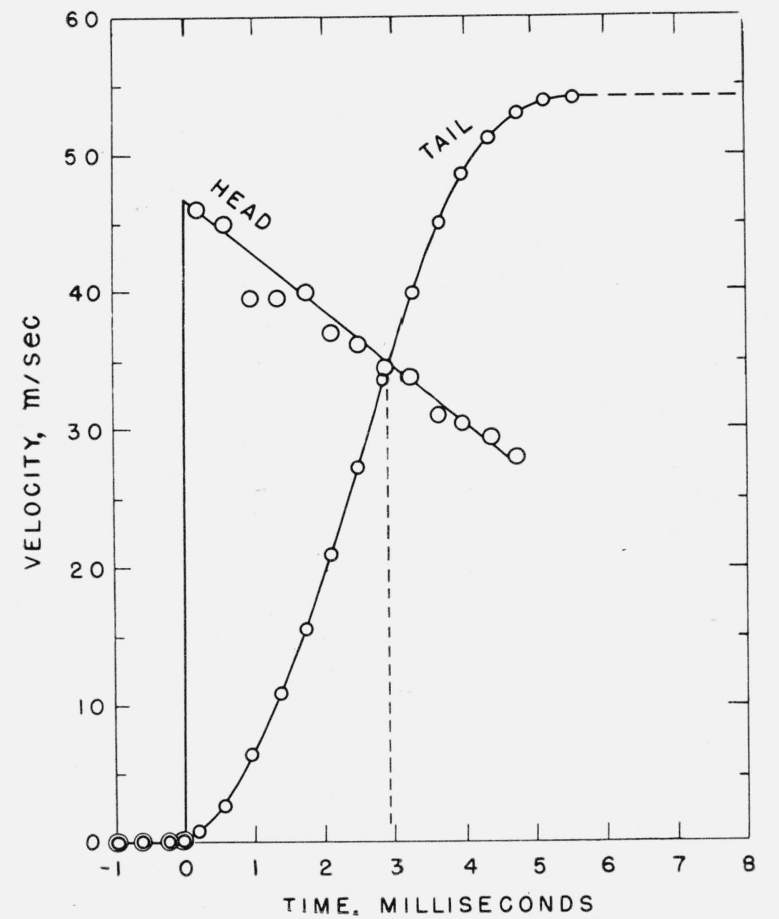

FIGURE 9. Velocity of head and of tail after impact in a test of a nylon yarn.

msec after impact when it attains the head velocity of $35 \mathrm{~m} / \mathrm{sec}$. It then increases less rapidly becoming essentially a constant, $54 \mathrm{~m} / \mathrm{sec}$, at 5 msec.

The slope of the velocity-time curve for the tailfigure 9, at any point (time) is equal to the accelera, tion of the tail. This acceleration is plotted against time in figure 10 . The maximum value is more than a million centimeters per second per second. Because the force on the tail (and thus on the specimen at the tail) at any time is equal to the mass times its acceleration, the curve in figure 10 is also a forcetime curve of the specimen at the tail. The ordinate scale given at the right side of figure 10 is in force units (kilograms). The curve in figure 10 thus indicates the force that the tail exerts on the specimen during loading and unloading. The total time for loading and unloading is only 6 msec in this test.

From figure 9 it is seen that the deceleration of the head at 3 msec after impact is approximately equal to one-fourth of the acceleration of the tail. As the mass of the head is about four times that of the tail it is evident that the force at the head is essentially equal to that at the tail.

In figure 8 the vertical distance between the distance-frame curve for the head, $\mathrm{A}$, and the distanceframe curve for the tail, $B$, at any frame (time) is equal to the length of the specimen at that time. The extension of the specimen at any time is given by the distance between the two curves at this time minus the distance between the two curves before impact. This extension is indicated graphically by the distance between curves $\mathrm{A}^{\prime}$ and $\mathrm{B}$, where $\mathrm{A}^{\prime}$ is the distance-frame curve for the head, A, after it was shifted down to $\mathrm{A}^{\prime}$ so that the portion before impact

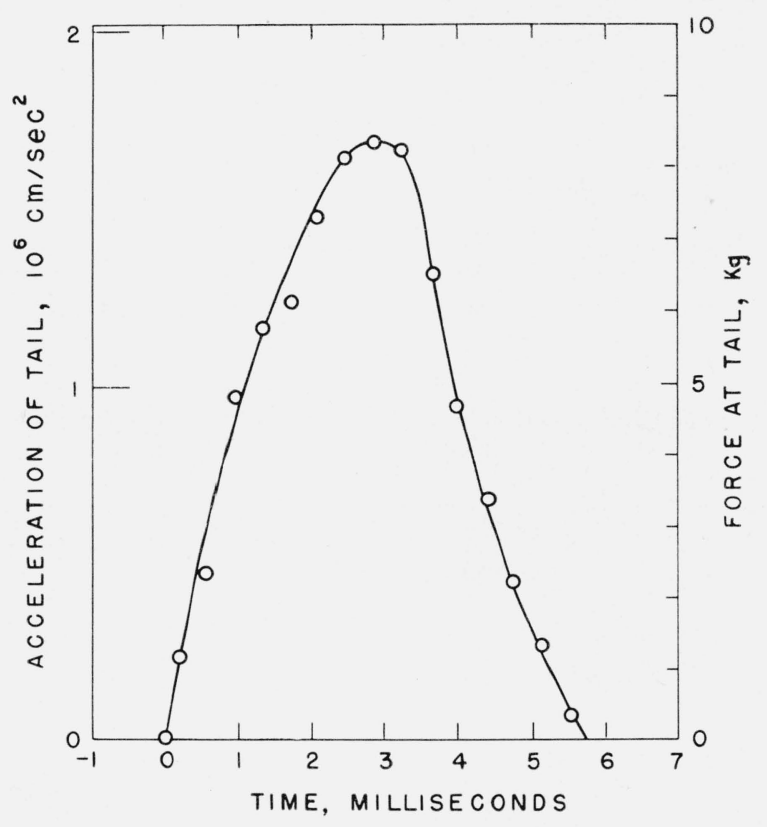

Figure 10. Acceleration of tail and force at tail after impact in a test on nylon yarn.

coincided with the similar portion of the curve B before impact. It can be seen that the extension (distance between curves $\mathrm{A}^{\prime}$ and $\mathrm{B}$ ) increases for times up to $3 \mathrm{msec}$, and then decreases. It is zero again at $6.7 \mathrm{msec}$ (frame 20). At this time, after impact, the head and the tail have moved the same total distance; that is, the length of the specimen (distance between head and tail) is again the same as before impact. If the specimen had recovered completely from its extension, it would have been under zero strain and zero tension at this instant. It was observed, however, that the specimen was already slack in frame 19 (6.3 msec after impact). The distance between the two curves at frame 19; namely, at $\mathrm{D}$, figure 8 , therefore represents the extension that remained after the specimen was completely unloaded. Part of this extension may have been recovered subsequently by delayed recovery. The extension during loading and unloading, expressed as a percentage of the specimen length before impact, and termed "elongation," is plotted against time in figure 11 . This elongation at any given time is the average elongation of the specimen. Actually, the elongation is not constant along the specimen, but shows a sharp increment at the strainwave front.

From the force-time curve in figure 10 and the elongation-time curve in figure 11 it is possible to plot simultaneous values of force and elongation. The result is a load-elongation curve for loading and also for unloading, as shown in figure 12 . The energy to maximum load is then readily obtained, as well as the energy recovered during unloading. The difference between these values, if converted into heat and assumed to be uniformly distributed throughout the specimen, would be sufficient to raise the tempera- 


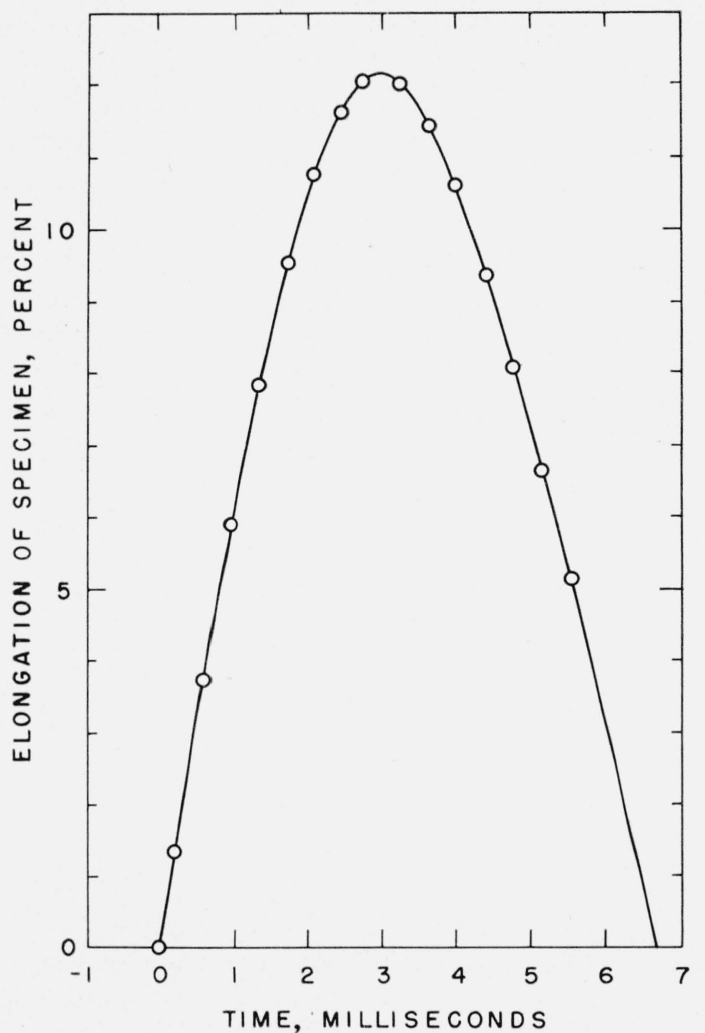

Figure 11. Average elongation of specimen after impact in a test on nylon yarn.

ture of the specimen about $10^{\circ} \mathrm{C}$. Actually, this hysteresis energy is not converted uniformly into heat throughout the specimen. For example, in another test in which the maximum strain was sufficient to rupture the specimen the fiber tips were fused, as shown in figure 13, which is evidence of high heat concentration at the point of rupture. This fused condition possibly results from the relatively low heat dissipation in nylon and the high localized energy released by bond rupture.

The points for the loading curve, broken line in figure 12, appear to lie systematically above and below the solid straight line that is drawn through them. The straight line indicates that at this high impact velocity the nylon specimen essentially obeyed Hooke's law during loading. However, the scatter of the points about the straight line is too consistent to be ascribed to experimental errors. It appears that this scattering of the points about the straight line is experimental evidence that the force at the tail varies in a stepwise manner. Each step in load indicates the arrival and reflection of a strain wave at the tail. It is significant to note that the individual points of the velocity-time curve for the head, figure 9 , show evidence that the deceleration of the head, and thus the force at the head, also varies in a stepwise manner. An analysis of these variations indicates that the time for the strain pulse to travel from the head to the tail, or $0.65 \mathrm{~m}$, is about $3 \times 10^{-4}$ sec. The velocity of strain propagation is therefore about $2,200 \mathrm{~m} / \mathrm{sec}$. The

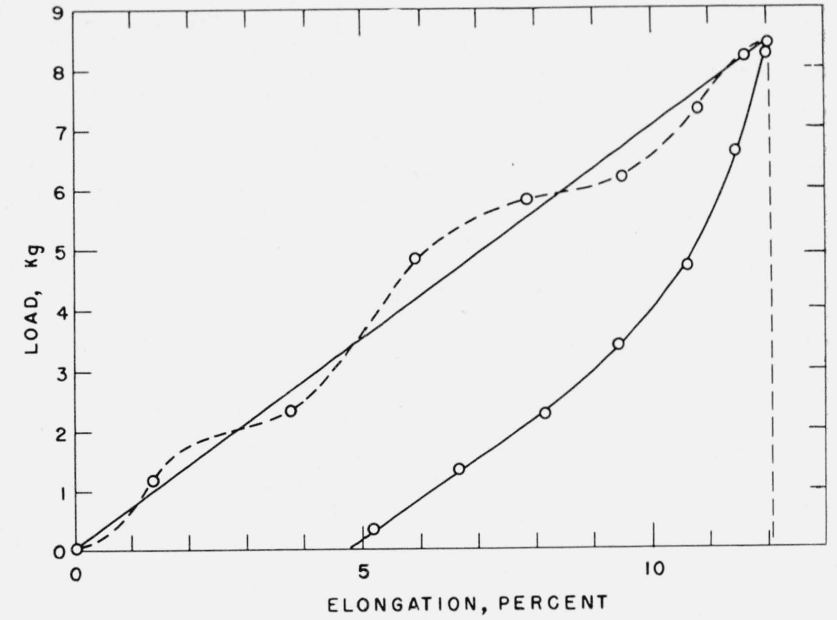

FIgURE 12. Load at tail plotted against average elongation for loading and unloading of a nylon yarn in an impact test.

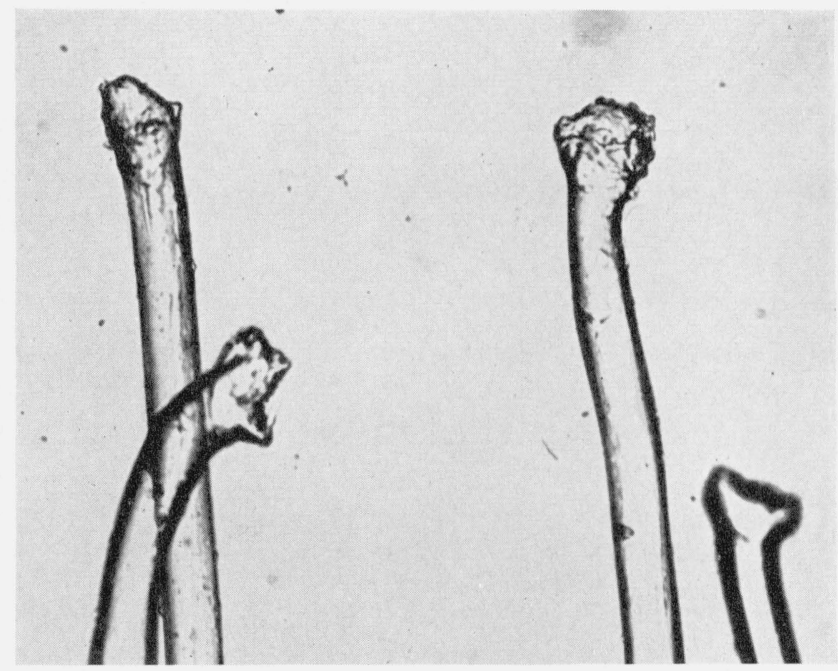

Figure 13. Magnified view of ruptured filaments of nylon showing fused ends.

strain at impact, given by the ratio of the velocity of the head at impact to the velocity of strain propagation, is thus about 2 percent. More detailed strain analyses for impact loading are given in subsequent papers [36, 37].

\section{References}

[1] J. B. Dickson, Functional properties in textile design, J. Textile Inst. 44, P514 (1953)

[2] J. B. Dickson and L. A. Davieau, Impact tester for textiles, AST M Bull. 198, 85 (1954).

[3] G. Glaser, Zur dynamischen Festigkeit von Bergseilen, Melliand Textilber. 24, 337, 377 (1943).

[4] E. R. Kaswell, Low temperature properties of textile materials, Am. Dyestuff Reptr. 38, P127 (1949).

[5] H. Leaderman, Impact testing of textiles, Textile Research J. 13, 21 (1943).

[6] W. J. Lyons and I. B. Prettyman, Use of the ballistic pendulum for impact testing of tirecord, Textile Research J. 23, 917 (1953). 
[7] R. Meredith, The effect of rate of extension on the tensile behavior of viscose and acetate rayons, silk, and nylon, J. Textile Inst. 45, T30 (1953).

[8] S. B. Newman and Helen G. Wheeler, Impact strength of nylon and sisal ropes, J. Research NBS 35, 41 (1945) RP1679.

[9] H. F. Schiefer, W. D. Appel, J. F. Krasny, and G. G. Richey, Impact properties of yarns made from different fibers, Textile Research J. 23, 489 (1953).

[10] A. H. Stang, M. Greenspan, and S. B. Newman, Dynamic tensile tests of parachute webbing, J. Research NBS 36, 411 (1946) RP1710.

[11] O. Andersson and B. Steenberg, Paper under impact conditions, Svensk Papperstidn. 53, 1 (1950).

[12] O. Andersson, An impulse method for measuring the impact strength of paper, Svensk Papperstidn. 56, 403 (1953)

[13] O. Andersson, A note on the application of mechanical models to studies of tensile properties of paper, Svensk Papperstidn. 56, 587 (1953).

[14] O. Andersson and L. Sjöberg, Tensile studies of paper at different rates of elongation, Svensk Papperstidn. 56, 615 (1953).

[15] J. W. Ballou and S. Silverman, Determination of Young's modulus of elasticity for fibers and films by sound velocity measurements, Textile Research J. 14, 282 (1944).

[16] W. R. Campbell, Determination of dynamic stressstrain curves from strain waves in long bars, Proc. Soc. Exptl. Stress Anal. 10, 113 (1952).

[17] W. R. Campbell, Dynamic stress-strain curves for mild steel using the tangent modulus procedure, J. Wash. Acad. Sci. 43, 102 (1953).

[18] J. D. Campbell, An investigation of the plastic behavior of metal rods subjected to longitudinal impact, J. Mech. and Phys. of Solids 1, 113 (1953).

[19] D. S. Clark and D. S. Wood, The time delay for the initiation of plastic deformation at rapidly applied constant stress, Proc. AST M 49, 717 (1949).

[20] J. D. Cole, C. B. Dougherty, and J. H. Huth, Constant strain waves in strings, J. Appl. Mechanics 20, 519 (1953).

[21] J. W. Craggs, Wave motion in plastic-elastic strings, J. Mech. and Phys. of Solids 2, 286 (1954).

[22] H. DeVries, On the elastic and optical properties of cellulose fibers (Drukkerij Fa Schotanus \& Jens, Utrecht, Holland, 1953)
[23] B. A. Dunnell and J. H. Dillon, The measurement of dynamic modulus and energy losses in single textile filaments subjected to forced longitudinal vibrations, Textile Research J. 21, 393 (1951).

[24] W. George, The measurement and physical interpretation of the mechanical strength of filaments, Textile Research J. 21, 847 (1951)

[25] R. D. Glauz and E. H. Lee, Transient wave analysis in a linear time-dependent material, J. Appl. Phys. 25, 947 (1954).

[26] W. Hamburger, The application of sonic techniques to the investigation of the effect of visco-elastic behavior upon stress-strain relationships in certain high polymers, Textile Research J. 18, 705 (1948).

[27] W. H. Hoppmann, The velocity aspect of tension-impact testing, Proc. AST M 47, 533 (1947).

[28] H. Kolksy, An investigation of the mechanical properties of materials at very high rates of loading, Proc. Phys. Soc. [B] 62, 676 (1949).

[29] E. H. Lee and I. Kanter, Wave propagation in finite rods of visco-elastic material, J. Appl. Phys. 24, 1115 (1953).

[30] R. Sips, Propagation phenomena in elastic-vicose media, J. Polymer Sci. 6, 285 (1951).

[31] B. Steenberg, Behavior of paper under stress and strain, Pulp \& Paper Mag. Can. 50, 207 (1949).

[32] T. von Kármán, On the propagation of plastic deformation in solids, OSRD Repo). No. 360, PB20276 (1942 rt

[33] T. von Kármán, The propagation of plastic deformation in solids, J. Appl. Phys. 21, 987 (1950).

[34] W. J. Lyons, Some theoretical considerations of dynamic property data on textile specimens, J. Appl. Phys. 21, $520(1950)$.

[35] D. S. Villars, Ultra speed tensile of rubber and synthetic elastomers, J. Appl. Phys. 21, 565 (1950).

[36] Frank L. McCrackin, Herbert F. Schiefer, Jack C. Smith, and Walter K. Stone, Stress-strain relationships in yarns subjected to rapid impact loading: 2 . Breaking velocities, strain energies, and theory neglecting wave propagation, J. Research NBS 54, 277 (1955) RP2590.

[37] Jack C. Smith, Frank L. McCrackin, and Herbert F. Schiefer, Stress-strain relationships in yarns subjected to rapid impact loading: 3. Effect of wave propagation, J. Research NBS $\mathbf{5 5}$ (in press).

Washington, December 17, 1954. 